\title{
The allotment in the restaurant: the paradox of foodie austerity and changing food values
}

\section{Abigail Wincott}

This is an uncorrected author manuscript of a chapter published in 2017 by Routledge in P. Bennett and J. McDougall (Eds) Hard Times Today: Austerity, Myth and Popular Culture. Abingdon: Routledge, pp. 28-41.

\section{Introduction}

This chapter explores the apparently paradoxical phenomenon of foodie austerity.

Paradoxical, because foodyism is about pleasure and consumption, while austerity is apparently about denial, and paradoxical because the simple dishes of poverty nostalgia are often sold at premium prices. This is not 'austerity' defined as cuts to public services. Nor is it necessarily 'austerity' as a reference to WWII and the immediate post-war era - a common cultural reference at the present time in Britain, and which has recently received some scholarly attention (see, for example, Bramall 2013, 2011, 2012; Potter and Westall 2013; Ginn 2012). Foodie austerity often looks to the past, certainly, but its relationship to the past is imprecise. It is part of a much wider movement born of dissatisfaction with modern food systems, which embraces the rediscovery and safeguarding of tradition and a turning away from mass production, from excess and convenience, towards the simple, the slow and the carefully made (Sassatelli and Davolio 2010).

My analysis of frugal foodyism draws on a large body of texts, including restaurant menus and promotional materials, cookery TV series and lifestyle sections of the British 'broadsheet' papers the Guardian, Observer and Telegraph. I also include articles about food poverty and comments 'below the line', which make use of the same spectrum of themes and arguments. 
There is naturally variation between texts and at times their concerns and tropes overlap with related discourses such as heritage foods, localism and environmentalism. Nevertheless there is a coherence to the repeated use of some themes in particular, which distinguish foody austerity from other similar projects, and which make it particularly ripe for scrutiny at this point in time, when the concept of 'austerity' is at the heart of debates about how countries and economies should be run. In this chapter I will therefore explore three key themes of frugal foody discourse, which allow an exploration of its nature and its potential political effects: a preference for the homely and the simple, the pleasures and virtues of self-restraint and an emphasis on care and labour in food production.

Austerity nostalgia in food has received some attention from academic writers and journalists, who have drawn attention to the dirty work it might do in delivering acquiescence to austerity in the sense of government spending cuts (Clarke and Newman 2012, 309). But the word 'austerity' is used in different ways in academic and journalistic analysis, as it is in popular culture.

Sometimes it is applied rather narrowly and at other times broadly, its different meanings not teased out and opened up for scrutiny. In the British context, terms like 'austerity chic' (Bramall 2012) and 'austerity nostalgia' (Hatherley 2009; Seymour 2013) have been used to refer to a love affair with WWII iconography and digging for victory - reference to the so-called austerity of the immediate post-war period and, by extension, wartime rationing. The word 'austerity' is of course also associated with cuts to welfare and other kinds of public spending, enacted in many countries around the world since the financial crisis began in 2007 (Bramall 2012), the reason for the timeliness of this collection. Popular culture makes promiscuous use of the various meanings of austerity and simplicity, and has done arguably since the crafts and self-sufficiency revival of the late 1960s and 1970s, articulating environmentalist arguments about food miles and 
pesticides to claims that simple home-grown food also tastes better, and ideas about the prudence of belt-tightening to the pleasure that can be drawn from learning traditional skills. Because of this, more work is needed which can take account of the breadth of this longstanding popular discourse of austere foodyism, while still investigating its contemporary political implications. In this chapter I investigate this broad spectrum of austere foodyism. By this I mean a celebration of self-restraint, of the 'simple pleasures' of humble foods of the historical poor, and of the labour and care which create 'wholesome' food, in contrast to an excess of industrially produced convenience food, carelessly made and thoughtlessly consumed.

Foodie discourse is increasingly politicised (Johnston and Baumann 2007, 2010) and food choices may also work as forms of protest. Protest through food does not only entail asceticism and renunciation, but occurs via the pursuit of alternative visions of pleasure and satisfaction (Soper 2007, 2008; Barnett, Littler, and Soper 2005). Discourses of simplicity in food may promise the reclaiming of sensory experiences, of care and of time, which appear to be lost in modern life (Sassatelli and Davolio 2010, 222). The idea of the 'austerity' in this wider sense draws on ideas about the past, though, as indicated above, that is by no means limited to wartime and post-war Britain. Texts betray an anxiety over a loss of knowledge and skills - about how to shop, how to grow and how to cook, which is sometimes expressed as consumers' loss of connection with food (Jackson, Ward, and Russell 2009, 16). Popular myths about modern industrial food tend to centre on the trope of loss: loss of genes, of habitat, of taste, loss of variety of cultures, which has given rise to movements to safeguard food heritage (Wincott 2015) in the form of endangered 'heritage' vegetable varieties, 'ancient' grains, rare breeds of meat animal and revived local food processes. 
The concept of free or cheap food is of course at the heart of frugal foodyism. But rather than penny pinching and belt-tightening, frugal foodyism is about simplicity, heritage, local and seasonal food, connection with producers and with where food comes from (see also David Evans' 2011 argument about the distinction between thrift and frugality). Frugal food can indeed be rather expensive if you dine out or shop at a specialist grocer's. The austere, the simple, the frugal in food and lifestyle are an extremely active set of themes in popular culture in the UK, seen everywhere from food blogs to restaurant interior design. Yet we still understand little about the ways austere food can be pleasurable, even indulgent and certainly expensive. How does the discourse of frugal foodyism add value added to simple, austere foods? And given the claims to accessibility and cheapness, how does it work to exclude some consumers, and produce differentiated food — as foodyism surely always must?

\section{Rustling something up: the homely, the humble and the simple}

The domestic and the home-made are privileged over the industrial in austere foodyism. In the past few years, it's become increasingly common in the UK to see restaurants and posh cafés offering homely and domestic kinds of dishes like porridge and prunes, toast and honey, cauliflower cheese or bacon sandwiches. They may even serve bubble and squeak, a dish traditionally made with left-overs. In fact, these cosy foods have become a marker of a certain kind of poshness. Regeneration in many British neighbourhoods is heralded by a refit of local pubs. Out go fitted carpets, velvet upholstery and an extensive menu of (frozen) foods from around the world, to be replaced with an 'austerity aesthetic' (Potter and Westall 2013, 155) of muted colour schemes, scrubbed pine tables, bare floorboards and a poverty nostalgia menu of simple, local foods, which remind patrons of the veg patch and home kitchen. Village East in the 
fast gentrifying district of Bermondsey, London, has even labelled sections of its menu '(bread) for the table', 'larder' and 'allotment'. Cabbages, cauliflowers and root vegetables have enjoyed a revival in professional kitchens, and austere foodie menus feature the kinds of vegetables found on allotments, such as Jerusalem artichoke and Swiss chard. This homely simplicity may not characterise the majority of meals eaten - even in austerity-chic settings, where luxury ingredients and exotic dishes may sit side by side on the menu with offal and cabbage - but it is nonetheless a discursive presence in the British foodscape (Bell and Hollows 2007, 36). The reworking of homely working class foods as gourmet indulgences for enlightened foodies can be seen especially clearly in the British lifestyle media, where advice on acquiring cookery skills and cultivating new tastes is often paired with learning to 'grow your own'.

Hugh Fearnley-Whittingstall's long running River Cottage franchise is a prime example. It comprises several TV series (Keo Films for Channel 4 2000-present) — where he experiments with self-sufficiency in a picturesque rural retreat, related books, a large website, and gardening and cookery courses, run from 'River Cottage HQ' in a Devon farmhouse (https://www.rivercottage.net/). River Cottage is all about the pleasures of growing and cooking your own food, but far more than this, it is about the pleasure of learning - and showing off new food-related skills. In the TV series, Fearnley-Whittingstall doesn't disguise his glee in competing with others, and in aiming to impress with both his newly acquired skills and the fruits of his labours via a range of competitions, stalls and staged events. River Cottage is now only one of many series relating good food to a return to the land and the re-learning of lost skills. Jamie Oliver's Jamie at Home series (Fresh One for Channel 4 2007, 2008) is similarly set in an idyllic kitchen garden, where Jamie is filmed picking produce to cook, and tips for growing food are included alongside recipes. The BBC has screened two series of the Big Allotment 
Challenge (Silver River for BBC 2014-2015) and during the filming of his series Simple Suppers (BBC 2009, 2010), Nigel Slater visits amateur growers on their allotments and cooks the day's harvest on a camping stove. These celebrity tastemakers also appear in the food and lifestyle sections of the $\mathrm{BBC}$ website and the broadsheet press, particularly the Guardian and its sister Sunday paper the Observer. Here, their writing promotes a discourse of food quality based on freshness, heritage and provenance. Good food is often associated with soil. In the Observer, Food writer Nigel Slater writes lovingly of Jerusalem artichokes and other root vegetables' 'honest goodness' and advises that:

One of the rules of good food shopping is that any vegetable sold with a coating of mud usually deserves a closer look. [...] The sacks of sand in which our family kept its home-grown parsnips and turnips saw them in fine fettle through till early spring. My own carrot crop is currently doing well simply by being left in the garden. Yes, muddy veg leaves a mess in the sink, but I enjoy washing their faces under a running cold tap to reveal their jewel-like colours. It is one of the many little pleasures of cooking. (Slater 2009)

In this passage, cooking with vegetables involves a rediscovery of lost shopping, growing, storage and preparation skills, but the pay-off is superior taste and some sensual pleasure. This pleasure is measured, not showy or wasteful, but prudent and frugal, like the habits of Slater generations past, with their home-grown root crops, carefully stored over winter. These newly rediscovered frugal foods are both a 'humble ingredient' but also 'rather sophisticated' (FearnleyWhittingstall 2008). With a knowing wink, Fearnley-Whittingstall suggests they can be transformed into 'swanky' and 'classy' dishes. They are best grown at home in the garden, where 'extracting them from the soil is like unearthing buried treasure.' Drawing attention to the connections between ingredients and a tradition of connection with the soil, and with lost knowledge about how to grow, shop and store, allows these tastemakers to present these foods as newly valuable, as an unearthed 'treasure'. It is possible for them to draw our attention to it 
because it is not the dominant way UK consumers generally come across their food these days. We find it grown, picked, washed and plastic-wrapped in the supermarket, or incorporated into ready-made foods. Through processing, the producers and retailers have added value and produced their profit margins but deskilled the consumer in the process. Nevertheless, simplicity and poverty are at the heart of the work of these foods, which leaves an uncomfortable tension, expressed in the ironic playfulness of Fearnley-Whittingstall's 'swanky' dishes.

Nigel Slater is another prominent proponent of British homely gastronomy. In spite of decades of experience as a food writer and author of recipe books, Slater has claimed in interviews and in his writing that he is an 'amateur' cook and situates his kind of cooking firmly in the domestic kitchen and kitchen garden, rather than the restaurant or gastro-pub (see, for example, Kanner 2012; Adams 2003, and his own website www.nigelslater.com/Nigel). His recipes often involve 'raiding the kitchen cupboards' and 'rustling up' food (Slater 2007; BBC 2010; Slater 2012) and he has made his mark with a brand of cookery which is ostentatiously unfussy, easy and quick. When a simple, homely supper is called for, many home cooks might reach for a tin of beans or a packet of crispy pancakes. Slater's fast food is set apart from mass produced convenience foods, his recipes generally calling for superior ingredients and incorporating subtle 'twists' - a feature of the food of the middle classes (Paddock 2015). As a Daily Mail reviewer puts it, they are 'a gentleman's idea of fast food' (Koski 2013). That review of Slater's 2013 book Eat: The Little Book of Fast Food provides a good summary of what makes Slater's food writing the epitome of humble foodyism:

There's nobody better than Nigel Slater at making cooking seem a relaxed, modest and wholly enjoyable affair, a 'let's do the show right here' pursuit where satisfying suppers can be rustled up from store cupboard ingredients and success is always on the menu. 
There is a 'but' implied here. The food seems relaxed and modest, 'rustled up'. Yet success here also means a challenge to produce food to impress others, to entertain, to learn new skills, to explore - it doesn't mean simply filling stomachs and putting food on the table. Yet its modesty relies on its association with the domestic kitchen and garden, producing just enough food to satisfy simple appetites. In this way competitive showmanship in the recipes of Slater, FearnleyWhittingstall and Oliver is hidden behind their repeated claims to simplicity, a lack of effort or deliberate planning (rustling up) and to making do (store cupboard ingredients, what's on the allotment).

Claiming to be making do with what's in the fridge or cupboard is one of many kinds of poverty claim made by cookery writers and chefs. In one interview, Raymond Blanc attempts to connect his sumptuous and well-staffed heritage kitchen garden at his Michelin starred restaurant le Manoir aux Quat' Saisons with childhood memories of working the land for his working-class parents (Gumming 2013). Food bloggers like the Skint Foodie or Frugal Queen buttress their positions as expert advisors on frugal living with reference to their former poverty (Morgan 2012; Frugal Queen 2015). The foodie conviction that a simple home-cooked meal is a healthy pleasure accessible to all reverberates in discussions in the British media, including in reader comments below articles about the rise of food poverty since 2007. These commenters return repeatedly to the austere foodie truism that basic home cooking with simple ingredients is the way the poor can put food on the table, like the bloggers and chefs, and they too tend to support their own claims to authority on the subject through reference to their experiences of poverty, past or present. An article in the Guardian's series 'Breadline Britain' entitled 'Families struggle to eat healthily amid rising food bills and shrinking budgets' (Hill 2012) is followed by a great 
deal of rather unforgiving below-the-line advice, which is buttressed by just these kinds of poverty claim:

Xeelee12: I can without any problem make a nutritious and tasty home-cooked meal for the price of a bag of chips... Anyway simple rye bread with something on it would be better than a bag of chips.

Yellapanda: myself and my husband live on a very low income and we enjoy growing our own, cooking our own and rising to the challenge of not having much money!

Stuart Lanigan: i have read the article, and, i'm not impressed... i'm disabled. [...] we have managed to bring up 2 lovely daughters, [... ] we have the healthy diets... and we have no debts... and we live on state benefits. one has to be creative, and frugal, but there are ingredients, and there is food. my wife cooks every day. we keep chickens and waste nothing. [...] we have learned to live a good, but simple life on $5 \mathrm{k}$ a year.

That idea of the good, simple life, available to all, is prevalent in modern British austerity

discourse but its requirements and rewards are not allocated to everyone in quite the same way.

\section{Good food and the luxury of self-restraint}

Aspirational downshifting lifestyle TV and broadsheet food writing - aimed squarely at middle-class foodies - emphasise the indulgent pleasure of simple, home-cooked food. But advice and comment for low-income families is far more concerned with self-restraint than gratification. Indeed, indulgence is often contrasted unfavourably with hard work and restraint, as if it, not unemployment, low wages or benefit cuts, were the root cause of poverty. No expenditure is too small to avoid censure. After reading Hill's article, yellapanda was moved to undertake some research and comments:

I certainly wouldn't choose to take my children to a softplay centre over buying nutritional food. I looked up the cost of taking two children to a softplay centre in Bristol - $£ 3$ each - so $£ 6$ could be saved if they were taken to a park - for free- instead. The extra $£ 6$ could be spent on providing fruit and a decent meal for all the family eg. 4 apples at $£ 1$, two head of organic broccili for $£ 1.40$ and some minced beef for the remainder. Add some potatoes, onions and stock you could have a decent shepherds pie served with nutritious veg and followed by an apple each. (Hill 2012)

Relaxation may be frowned upon: 
So he slumps down on the sofa and reaches for the remote control, rather than trying to cook something healthy, cheap and non processed. Good, cheap food is all about time. How on earth did our grand parents manage it? (Grumpybear, Hill 2012)

If you honestly don't have half an hour to cook, what the hell *are* you up to all evening?' (Jonman, commenting on Ebner 2006)

And for some commenters, state benefits enable this easy and slothful food regime:

Poor people are poor because they make poor lifestyle choices [...]. Breaking this cycle is very difficult - could help with withdrawal of benefits therfore starving people into making appropriate life choices - who knows? (sekunder commenting on Dalrymple 2013)

That options should be limited for those on benefits or low wages seems unsurprising, but limited options are a central element of the ethic of modern foodyism, regardless of ability to pay. It's not always a restraint which is imposed, as it was through the rationing and poverty of mid-twentieth century austerity. It is rather the 'self-imposed austerity, restraint, reserve' of those who have not perhaps the most financial capital, but who do have cultural capital - the educated middle classes (Bourdieu 1984, 176). Plentiful choice and convenience are available daily in supermarkets and fast food outlets across the land. They thus offer little opportunity for social distinction and they are too easy to offer much of a sense of reward for the aspirational middle-classes. In frugal foodyism, restraint is apparent in the often narrow menus of 'good' restaurants and cafes. In publicity materials these establishments boast about the limitations they impose - committing to using only fresh, only local, only organic or 'heritage' meat and vegetables, to cook only what is in season. Eating seasonally is a performance of self-discipline in an age of air-freight and freezers. A lot of restaurants and upmarket cafés go so far as to declare that their menus will be decided on a daily basis, in response to what has been delivered or sourced on the day. For example, Heirloom in North London claims 'our menus are created 
around what we pick on a daily basis' and the St John restaurant in Spitalfields warns impatient clientele sternly:

Our menu is a daily work in progress, which means that the menus won't go online until 11am for lunch and $5 \mathrm{pm}$ for supper. There will often be specials during service where fresh good things have been delivered by our farmers and producers.

This acceptance of inconvenience and limitation, in an economy where choice and plenty are the norm, doesn't only offer distinction because of its uncommonness. It draws on and supports the widespread championing of local produce and local producers, as a solution to the problems with modern industrial food systems and which is associated with the development of alternative food networks (Paddock 2015; Potter and Westall 2013; Darnton et al. 2009). Self-imposed constraints on food all privilege production over consumption and retail, drawing attention to producers and their needs. This is supported by talk of provenance and the 'sourcing' of the finest produce for the consumer in menus and promotional texts. The very fact that the chef and customer must wait to see what the producer delivers on the day is an interesting prioritising of the grower over the consumer. Where factory-made food draws a veil over production processes and ingredients, 'alternative' foodie texts revel in details about where food is produced, by whom and how. ${ }^{1}$

\section{The work ethic of austere food}

The work of food production is foregrounded, then, as we have seen, and this work is key to the value and meaning of frugal foodyism. There are several kinds of work to which attention is

\footnotetext{
${ }^{1}$ There is an interesting literature about food commodity fetishization, which there is not the space to do justice to here, but see Gunderson (2014) and Cook and Crang (1996) for an introduction, and Bramall (2013) on austerity discourse in particular.
} 
drawn. Each adds different kinds of value. There is also backgrounded or under-recognised labour - because not everyone's effort is valued in foodie discourse.

The work of making something yourself at home, made possible through the revival of old skills, is often associated with thriftiness, as we have seen in some of the reader comments about life on a low income. Cooking your own food from scratch, rather than buying ready-made foods, or growing your own herbs or vegetables may well save money, through the spending of time, effort and skill. Commenters thus present re-skilling and pleasurable work as one answer to escaping uninvited austerity produced by cuts to benefits, wage freezes and job losses. They suggest we can seize the opportunity to live well in spite of economic constraints imposed from outside. There are also those who simply advocate shopping around for the cheapest food, the best bargains, vouchers and special offers. But what makes reskilling different from bargain hunting is the way that the foodie's own skill and labour make possible not only liberation from economic woes but liberation from corporations - the agricultural bio-tech giants, the food processors and the supermarkets. These comments are taken from the Guardian website (The first two from Hill 2012; and the third from Ebner 2006):

ArgueInAnEmptyRoom: 'Cheaper' food doesn't have to be less appetising or less healthy if people develop proper cooking (and shopping) skills and try to liberate themselves from the supermarkets if they can.

Thomomatic: we (as the common poor working or middle class people) don't have access to resources, it is all outsourced to governments and big corporations. Instead, we should have access to land to grow our food and have the ability to dictate our own future and not rely on market forces and "global economy".

Walneygirl: 'Oh Sarah, you've fallen into the not-enough-time fallacy! The one propagated by a system which expects you give your first priority to your employer instead of yourself and work the longest hours in Europe, and which tells you repeatedly that cooking properly means hours spent in the kitchen. It doesn't of course - it's a myth propagated by the supermarkets who want you to pay them a premium to them for 'convenience'. How do I manage to run a business and make proper meals? Easy - I'm in control of my time. 
Reskilling is a concept which has been popularised by the large Transition movement, which has been adopted by several British towns. The transition movement's literature tends to foreground environmental concerns, but in a way which contains an implied critique of corporate capitalism, and the movement's strategy centres on the development of local food co-operatives, community seed swaps and reskilling classes (Transition Network 2013) as a way of reviving localism and building community resilience. Food reskilling is often framed as an opportunity to wrest some independence from the big corporations, who profit from every stage of the food chain from field to plate, a way of asserting your own food sovereignty in the home (Stoddart 2014). In this way, home-labour is rediscovered as a means to solving economic, political, health and green worries, through learning home fermentation (Venner 2013) or sourdough bread baking (Du Cann 2015).

Those with the means may purchase these things by visiting artisan bakeries, farm shops and farmers' markets, or cafes and restaurants. The retailed food of simple gastronomy bears many signs of care and labour, just like its home-made counterpart. The food may be 'rustic' in appearance, showing the mark of hands which made it and differentiating it from factory-made food, which has marks made by the pipes, spikes and stamps of machinery. The expenditure of time and skilled labour are often advertised. A browse through some restaurant menus shows the Alford Arms in the Chilterns hamlet of Frithsden offers 21-day aged steak, 'hand-cut' chips and slow roasted garlic. Meanwhile, the dinner menu of the Black Rat in Winchester reveals it is one of a number of British restaurants which grows its own food: 'We have our own forager, and grow vegetables and herbs in our allotment down the road from the restaurant'. Restaurant and café chain Peyton and Byrne's website stresses that the food is cooked 'with respect' but also 
'flair' and 'passion'. So 'good' food is made valuable not only by labour, but is even artistic, a word echoed in 'artisan', a label nowadays so often applied to high quality food made by smallscale producers. This food-work is distinguished not only by human hands, then but by care and artistry and by the time spent producing food slowly, unlike the intricate, impressive and highspeed work performed by machines in food factories. As Bourdieu observed, time is one of the most rigorous anthropological limits $(1984,281)$. Moreover, wealthier consumers find their time is worth more and more financially. Thus the labour which offers empowerment and pleasure to those who have no money also adds a great deal of value to frugal food as a commodity for the well-to-do.

It should be noted though that it is not only the well-paid whose time is scarce. The problem with frugal foodyism's proposal that skill and labour offer the answer to poverty is that many people on low incomes are also time-poor and yet cannot purchase time and skill by proxy. For those with little time to spare in particular, the pleasures and empowerment enabled by the work of frugal living cannot be disentangled from food-labour as burden. And the burdens and pleasures are not equally shared, between men and women, or across economic classes (Parkins and Craig 2006, 114; Bell and Hollows 2007). Advice to those on a low income often exhorts the poor to plan and organise every aspect of food provisioning, from growing, through shopping, to dealing with leftovers: 'Planning, planning, planning is paramount' as Mumsnet has it (www.mumsnet.com/family-money/money-saving/eat-on-the-cheap) in order to survive. In an Observer Food Monthly advice piece with blogger the Skint Foodie entitled 'How to eat well on a tight budget' (Morgan 2012), we are advised that 'impulsive spending isn't an option'. Each week's menu should be planned in advance, and shopping lists should be no more than the list of these ingredients in their exact quantities. Many online comments beneath articles on food 
poverty also make claims about the rigorous planning undertaken by the commenter. These include visiting price comparison websites for groceries, visiting several stores in turn to find the lowest prices, cooking and freezing several portions, planning meals which use leftovers and organising packed lunches the night before 'no excuses' (abutler in Hill 2012). This thrifty provisioning therefore requires a lot of time and physical and mental effort. It is invisible and repetitious work, not for pleasure, but simply to keep a family fed. Readers' comments in particular often argue that the caring work of provisioning for loved ones is central to being a good parent. Claims that scrimping and saving or slaving over a stove are an unfair and unequally distributed burden are given short shrift in general (see, for example, Ebner 2006; Hill 2012).

\section{Conclusion: Austerity and its contradictions}

There are a number of tensions in austere foodie discourse: between pleasure on the one hand, and self-denial and hard work on the other; between the accent on domesticity, but the love of the expert and artisanal, between the expense, where these foods are for sale, and thrift where they are home-grown or home-made. The retail value of frugal food is produced by the discursive activities of numerous journalists, TV chefs, restaurants, commenters and bloggers, which holds these contradictory ideas in tension through their ironic stance and their insistence on the ease of finding an alternative kind of luxury through austere living.

We shouldn't dismiss this as an illusion, playing at farm-work like latter-day Marie Antoinettes. Nor can we reduce it to a convenient ploy by the wealthy and powerful to enable austerity in the form of cuts to welfare and wages. The transformation of what was homely and basic to products which are desirable and expensive is made possible through related and 
intersecting discourses of environmentalism, critiques of the effects of globalised corporate capitalism, and fears about the health effects of industrial foods and the modern Western diet. That is to say, its value signals widespread desire for change.

The problem at the present time in British popular culture is perhaps rather the dominance of one particular take on frugality: as a personal project for self-improvement. There are alternative, collectivist approaches to new frugality, such as political campaign movements espousing a return to the land like Reclaim the Fields or La Via Campesina, which lobbies for rights of access to growing and making food at an inter-governmental level. There is the concept of conviviality important to many in the Slow Food movement and there are food or farming cooperatives and community vegetable gardens in operation around the UK. However, at the present time, lifestyle media and retail have the loudest voice and their individualist discourse of pleasurable austerity is presumably particularly frequently encountered by those who find it attractive and seek out its products, programmes and websites.

Consumer activism's strength - that each of us can be powerful agents for change and seize our freedoms - is also closely allied to its weakness. That is, it tends to responsibilise the individual and let government off the hook (Maye, Goodman, and Holloway 2010, 1785) with regards to increasing poverty in British society, drawing attention away from structural problems of the globalised free market, despite the fact that these concerns lie at the heart of austerity food's appeal. Advice routinely given to hard-up families shows the same themes, drawn from lifestyle and retail frugalism, supporting the assumption that, if it is so easy and pleasurable to learn your way to a simpler, better life, then the poor must logically be lacking the will and selfdiscipline to change or ignorant and in need of education. Austere foodyism has been very effective at hiding the reality of life on the bread line. 


\section{References}

Adams, Tim. 2003. While other boys in his class were reading Shoot! Nigel subscribed to Cordon Bleu magazine. The Observer, 14 September.

Barnett, Clive, Jo Littler, and Kate Soper. 2005. Consumers: Agents of change? Soundings (31):147-160.

BBC. 2009, 2010. Simple Suppers. BBC 1.

—. 2015. Making It Up Isn't Making Do, Series 1, Nigel Slater's Simple Suppers - BBC One 2010 [cited 7/6/15 2015]. Available from http://www.bbc.co.uk/programmes/b00mq461.

Bell, David, and Joanne Hollows. 2007. Mobile Homes. Space and Culture 10 (1):22-39.

Bourdieu, Pierre. 1984. Distinction : a social critique of the judgement of taste. Translated by R. Nice. Cambridge, Mass.: Harvard University Press.

Bramall, Rebecca. 2011. Dig for victory! Anti-consumerism, austerity and new historical subjectivities. Subjectivity 4 (1):68-86.

- 2012. Popular culture and anti-austerity protest. Journal of European Popular Culture 3 (1):9-22.

—. 2013. The austerity larder: Mapping food systems in a new age of austerity. Journal of Consumer Culture.

Clarke, John, and Janet Newman. 2012. The alchemy of austerity. Critical Social Policy 32 (3):299-319.

Cook, Ian, and Philip Crang. 1996. The World On a Plate: Culinary Culture, Displacement and Geographical Knowledges. Journal of Material Culture 1 (2):131-153.

Dalrymple, Theodore. 2013. It's not poverty that's fattening - it's the bad eating habits. the Telegraph, 23 January.

Darnton, Andrew, Paul White, Veronica Sharp, Phil Downing, Alex Inman, Kit Strange, and Tara and Garnett. 2009. Food Synthesis Review Summary Report: A report to the Department for Environment, Food and Rural Affairs. London: DEFRA.

Du Cann, Charlotte. 2015. Bread of heaven. Writing in Transition blog 2015 [cited 17 June 2015]. Available from http://charlotteducann.blogspot.co.uk/2015/06/bread-ofheaven.html.

Ebner, Sarah. 2006. Real food isn't real life. The Guardian, 21 September

Evans, David. 2011. Thrifty, green or frugal: Reflections on sustainable consumption in a changing economic climate. Geoforum 42 (5):550-557.

Fearnley-Whittingstall, Hugh. 2008. Knobbly needs. The Guardian, 2 February.

Fresh One for Channel 4. 2007, 2008. Jamie at Home.

Frugal Queen. 2015. Coping with austerity. 
Ginn, Franklin. 2012. Dig for Victory! New histories of wartime gardening in Britain. Journal of Historical Geography 38 (3):294.

Gumming, Ed. 2013. French chef English heritage. The Daily Telegraph, 20 April.

Gunderson, Ryan. 2014. Problems with the defetishization thesis: Ethical consumerism, alternative food systems, and commodity fetishism. Agriculture and Human Values 31 (1):109-117.

Hatherley, Owen. 2009. Lash out and cover up: austerity nostalgia and ironic authoritarianism in recession Britain. Radical Philosopy 157:2-7.

Hill, Amelia. 2012. Families struggle to eat healthily amid rising food bills and shrinking budgets. The Guardian, 18 November.

Jackson, Peter, Neil Ward, and Polly Russell. 2009. Moral economies of food and geographies of responsibility. Transactions of the Institute of British Geographers 34 (1):12-24.

Johnston, Josée, and Shyon Baumann. 2007. Democracy versus Distinction: A Study of Omnivorousness in Gourmet Food Writing. The American Journal of Sociology 113 (1):165-204.

—. 2010. Foodies: Democracy and distinction in the gourmet foodscape. London and New York: Routledge.

Kanner, Ellen. 2012. Nigel Slater: The professional amateur. Culinate, 27 March.

Keo Films for Channel 4. 2000-present. River Cottage.

Koski, John. 2013. Food book of the week: Eat: The Little Book of Fast Food by Nigel Slater. Daily Mail, 6 October.

Maye, Damian, Michael K. Goodman, and Lewis Holloway. 2010. Ethical foodscapes?: premises, promises, and possibilities. Environment and Planning A 42 (8):1782-1796.

Morgan, Eleanor and the Skint Foodie. 2012. How to eat well on a tight budget. Observer Food Monthly, 13 July.

Paddock, Jessica. 2015. Invoking Simplicity: 'Alternative' Food and the Reinvention of Distinction. Sociologia Ruralis 55 (1):22-40.

Parkins, Wendy, and Geoffrey Craig. 2006. Slow living. Oxford: Berg.

Potter, Lucy, and Claire Westall. 2013. Neoliberal Britain's Austerity Foodscape: Home Economics, Veg Patch Capitalism and Culinary Temporality. new formations: a journal of culture/theory/politics 80 (80):155-178.

Sassatelli, Roberta, and Federica Davolio. 2010. Consumption, pleasure and politics: Slow Food and the politico-aesthetic problematization of food. Journal of Consumer Culture 10 (2):202-232.

Seymour, Richard. 2013. 'Austerity cooking' has been hijacked by the moralisers. The Guardian, 28 August.

Silver River for BBC. 2014-2015. The Big Allotment Challenge. 
Slater, Nigel. 2007. Lunch with a crunch: With the blossom in full swing, Nigel Slater rustles up a simple but hearty meal of broad beans, leeks and bacon to welcome in the spring. The Observer, 27 March.

—. 2009. Coming back down to earth. The Observer, 4 January.

- 2012. The pie that came in from the cold: A plate of steaming carbs is the perfect antidote to a chilly day. Nigel rustles up a cottage pie full of mellow flavours. The Observer, 12 February.

Soper, Kate. 2007. Rethinking the 'Good Life': The citizenship dimension of consumer dissafection with consumerism. Journal of Consumer Culture 7 (2):205-229.

- 2008. Alternative hedonism, cultural theory and the role of aesthetic revisioning. Cultural Studies 22 (5):567-587.

Stoddart, Kim. 2014. Seed saving: an introduction. The Guardian.

Transition Network. What is a Transition Initiative? 2013 [cited 20 July 2015. Available from https://www.transitionnetwork.org/support/what-transition-initiative.

Venner, Grant. Reskilling Day 2013 report. Ealing Transition website 2013 [cited 17 June 2015. Available from http://ealingtransition.org.uk/reskilling-day-2013-report/.

Wincott, Abigail. 2015. Heritage in danger or mission accomplished? Diverging accounts of endangerment, conservation and 'heritage' vegetables in print and online. Food, Culture and Society 18 (4). 